\title{
The Reflection Room: Participatory art installations to move us from death-denying to death-discussing
}

Paul Holyoke, PhD, SE Research Centre, SE Health, Canada

Barry Stephenson, PhD, Dept of Religious Studies, Memorial University, Canada

Contact: paulholyoke@sehc.com, bstephenson@mun.ca

Issue

Choice at end of life depends on talking about dying. ${ }^{1}$

Fear and denial are part of the reluctance to talk about death. ${ }^{2,3}$

\section{Theoretical foundation}

People are more likely to discuss death if they are exposed to it through experience. 4,5 Hearing or reading stories can increase the familiarity with dying and be a catalyst to talking about dying. 5
The study

We provided 39 non-coercive spaces across Canada to give people an opportunity to tell and read stories about dying.

Visitors to "pop-up" Reflection Rooms can read others' stories, leave a reflection, or simply enjoy the space. A survey collects data on comfort about talking about dying.

Installations - examples
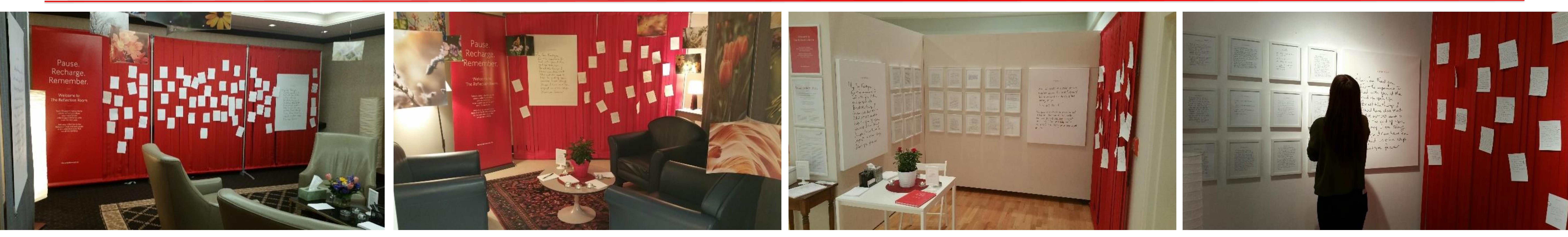

Results - themes from stories left in the Reflection Rooms

Gratitude, promises, regret
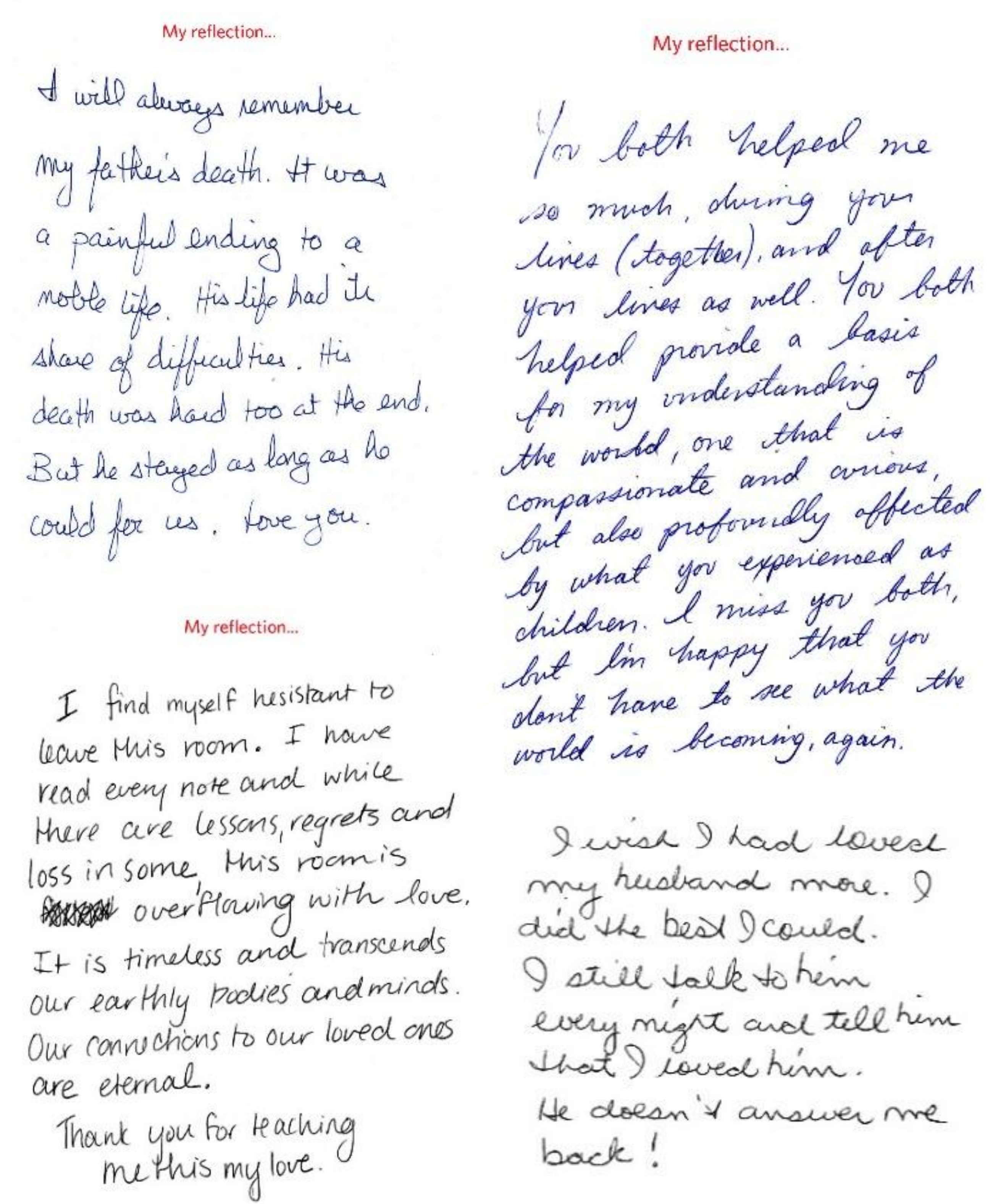

Results - surveys

70 said visiting the Reflection Room $70 \%$ increased their comfort with talking about dying and death

Three months later

$73 \%$ said visiting the Reflection Room increased their comfort with talking about dying and death
Working through grief
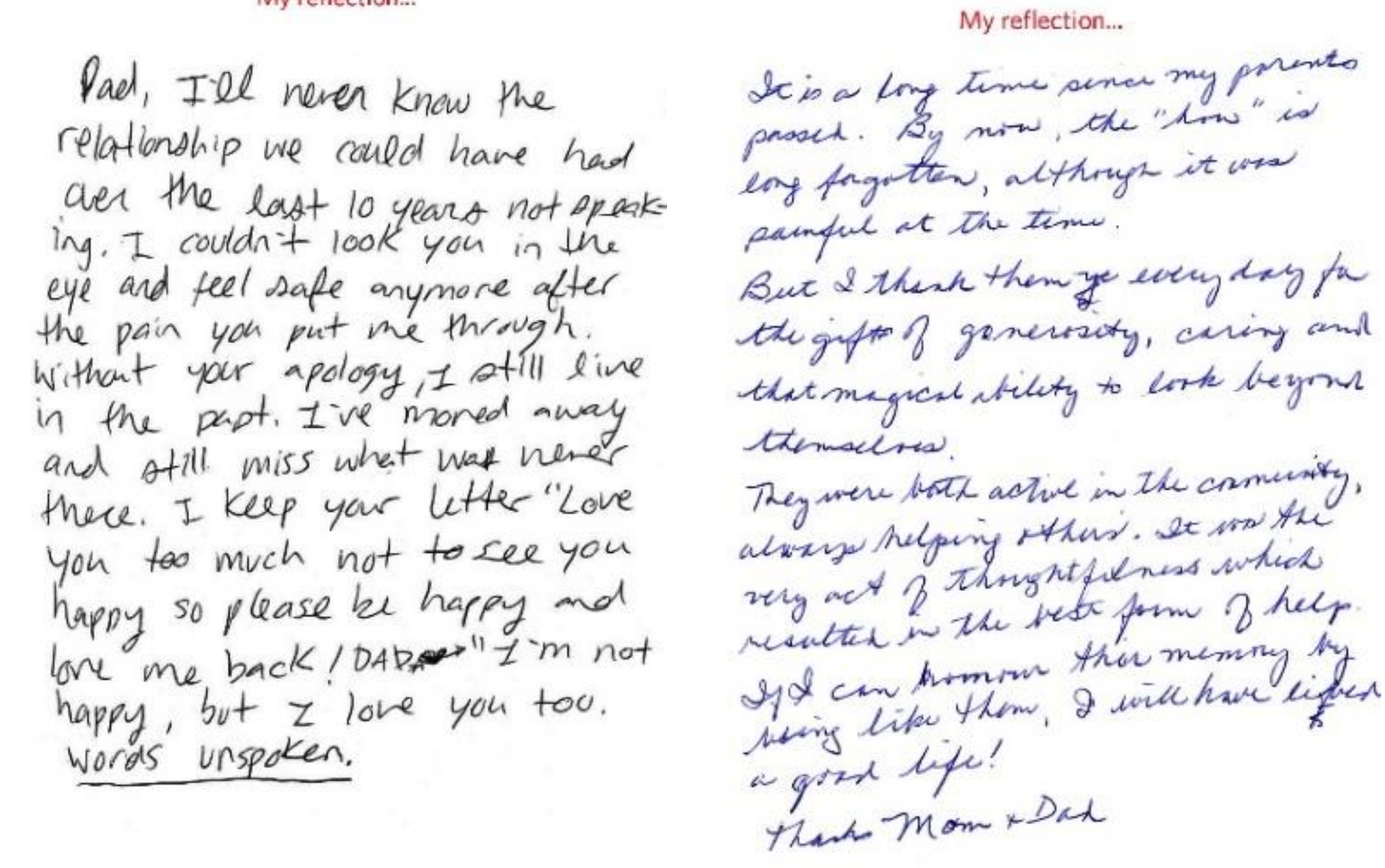

I wrote a reflection, but couldn't post it when I was done. I ripped it up and discarded it. But I do feel this was extremely helpful. It brought me some closure and peace. Thank you for this.

I laved the fact that at firsst I could not stay in the room.... It brought out too many emotions. After going back several times, I felt calm and I was the thinf, reffect and feel better. I am a person who believes in talking and expressing wishes around death, but this was a healing process for me also, (comment from a survey form)
Letters to the dead

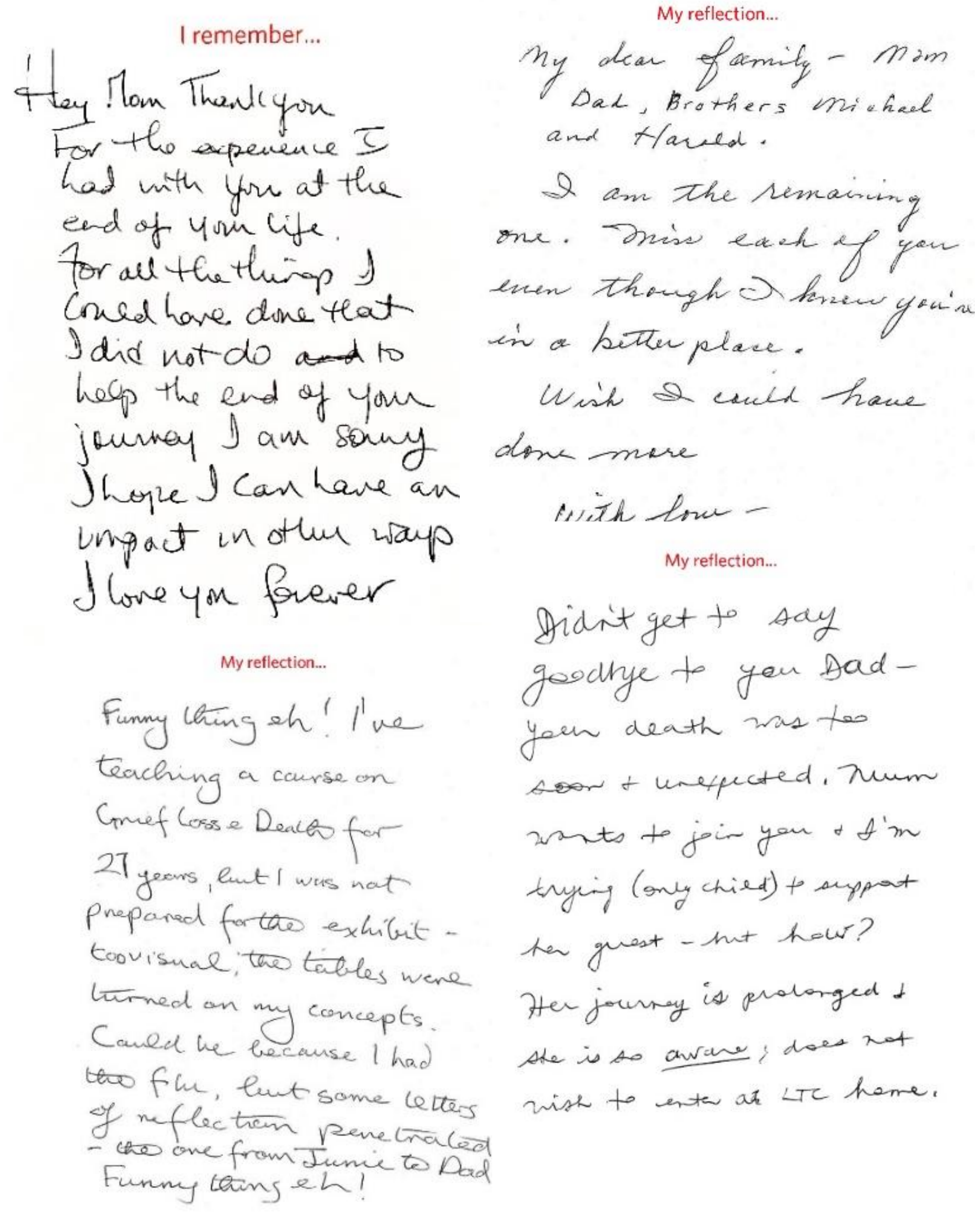

\section{$79 \%$ \\ said they were more likely to talk to their family and friends about dying and death}

$79 \%$ said they had talked to their family and friends about dying and death
$82 \%$ said they were more likely to think about planning for their own death said they had started about planning for their own dying and death

\section{Discussion}

Physical space and time open emotional space to become more comfortable about talking about death. Helping more people move from discussion to planning requires more investigation.

\begin{tabular}{c|c} 
Death & $\begin{array}{c}\text { Death } \\
\text { denying }\end{array}$ \\
\end{tabular}

